\title{
Produtos extrusados expandidos de misturas de canjiquinha e soja para uso como petiscos ${ }^{(1)}$
}

\author{
Marilene dos Santos Fernandes(2), Sin-Huei Wang(2), José Luis Ramírez Ascheri( ${ }^{(3)}$, \\ Myriam Ferreira de Oliveira ${ }^{(2)}$ e Simone Aparecida James Costa(2)
}

\begin{abstract}
Resumo - O objetivo deste trabalho foi estudar o efeito da temperatura de barril (TB) do extrusor no índice de expansão (IE) e no índice de solubilidade em água (ISA) dos produtos extrusados expandidos de misturas de canjiquinha e soja (80:20 e 70:30), e verificar suas características sensoriais, quando aromatizado para uso como petiscos. Foi usado o extrusor Brabender de dupla-rosca, com velocidade de alimentação constante de $20,8 \mathrm{~kg} / \mathrm{h}$, velocidade da rotação de parafuso de $100 \mathrm{rpm}$ e diâmetro de matriz de $5 \mathrm{~mm}$. As temperaturas de barril do extrusor foram constantes na zona $1\left(60^{\circ} \mathrm{C}\right)$ e na zona $2\left(90^{\circ} \mathrm{C}\right)$ e variáveis na zona $3\left(90,110,130\right.$ e $\left.150^{\circ} \mathrm{C}\right)$ e na zona $4\left(110,130\right.$ e $\left.150^{\circ} \mathrm{C}\right)$. O IE e o ISA dos produtos extrusados expandidos aumentaram com o aumento da TB na zona 3 até $110^{\circ} \mathrm{C}$; acima desta temperatura, observou-se diminuição desses índices. O aumento da TB na zona 4 resultou em aumento no IE e ISA, exceto quando os produtos haviam sido submetidos a 130 e $150^{\circ} \mathrm{C}$ na zona $3 . \mathrm{O}$ produto extrusado expandido contendo $80 \%$ de canjiquinha e $20 \%$ de soja, submetido às temperaturas de barril de 60,90 , 110 e $150^{\circ} \mathrm{C}$ e aromatizado com cebola, apresentou melhor aparência, textura e sabor, e foi preferido pelos consumidores. Não houve atividade do inibidor de tripsina nos produtos estudados.
\end{abstract}

Termos para indexação: extrusão, farinha, petisco, textura, sabor.

\section{Puffed extruded corn-grits and soybean mixtures for snack use}

\begin{abstract}
The objective of this work was to study the effect of barrel temperature (BT) on expansion ratio (ER) and on water solubility index (WSI) of puffed extruded corn-grits and soybean mixtures (80:20 and 70:30) and to verify their sensory characteristics, while flavored for snack use. Brabender twin-screw extruder with a constant feed rate of $20.8 \mathrm{~kg} / \mathrm{h}$, a constant screw speed of $100 \mathrm{rpm}$ at an extruder exit through $5 \mathrm{~mm}$ die was used. The extruder barrel temperatures were zone $1\left(60^{\circ} \mathrm{C}\right)$ and zone $2\left(90^{\circ} \mathrm{C}\right)$ and they were variable in zone $3\left(90,110,130\right.$ and $\left.150^{\circ} \mathrm{C}\right)$ and zone $4(110,130$ and $150^{\circ} \mathrm{C}$ ). An increase up to $110^{\circ} \mathrm{C}$ in BT at zone 3 caused an increase in ER and WSI of puffed extruded products and above $110^{\circ} \mathrm{C}$ caused a reduction in these indexes. An increase in $\mathrm{BT}$ at zone 4 resulted in an increase in ER and WSI, except for puffed extruded products submitted to 130 and $150^{\circ} \mathrm{C}$ in zone 3 . Puffed extruded product with $80 \%$ corn-grits and $20 \%$ soybean, submitted to BT at $60,90,110$ and $150^{\circ} \mathrm{C}$ and flavored with onion, presented better appearance, texture and flavor, being the preferred by consumers. No trypsin inhibitor activity was detected in the products.
\end{abstract}

Index terms: extrusion, flours, snack foods, texture, flavour.

\section{Introdução}

A elaboração de produtos expandidos por meio do processo de extrusão tem crescido notavelmente

(1) Aceito para publicação em 12 de abril de 2002.

(2) Universidade Federal Rural do Rio de Janeiro, Dep. de Economia Doméstica, BR 465, km 47, CEP 23890-000 Seropédica, RJ. E-mail: marilenesfernandes@bol.com.br, sin-hueiwang@bol.com.br, myriamfo@bol.com.br, simonejames@zipmail.com.br

(3) Embrapa-Centro Nacional de Pesquisa de Tecnologia Agroindustrial de Alimentos, Av. das Américas, 29501, CEP 23020-470 Guaratiba, RJ. E-mail: ascheri@ctaa.embrapa.br nos últimos anos. Em geral, a extrusão resulta em gelatinização de amido, desnaturação de proteína, formação de complexos entre amido e lipídio e entre proteína e lipídio (Mercier et al., 1980). Estas mudanças, segundo Chen et al. (1991), influenciam na aparência, aroma, sabor e textura dos produtos extrusados.

O volume de expansão é o indicador de qualidade primário associado com a crocância, a dureza e a mastigabilidade de produtos extrusados expandidos (Chen et al., 1991). Alguns trabalhos têm avaliado o papel de variáveis do processo de extrusão como temperatura de barril, configuração de rosca, tama- 
nho e forma da matriz, velocidade de rosca e conteúdo de umidade, sobre a expansão de produtos contendo farinha ou amido de milho (Owusu-Ansah et al., 1983; Chinnaswamy \& Hanna, 1988). Características das matérias-primas, tais como conteúdos de proteína, lipídio e amido, sua composição e seu tipo, também afetam o volume de expansão dos produtos extrusados (Launay \& Lisch, 1983; Chinnaswamy \& Hanna, 1988).

A soja tem sido reconhecida como excelente fonte para melhorar o perfil de aminoácidos e aumentar conteúdos totais de proteína e alguns minerais como $\mathrm{P}, \mathrm{Ca}, \mathrm{K}, \mathrm{Na}, \mathrm{Mg}$, Fe e Cu em produtos de milho (Zoia et al., 1997; Borges et al., 1999). A mistura de milho e soja processada por extrusão tem sido estudada por vários autores (Lorenz \& Jansen, 1980; Guzman et al., 1989).

O presente trabalho teve por objetivo estudar o efeito da temperatura de barril do extrusor no índice de expansão e no índice de solubilidade em água dos produtos extrusados expandidos de misturas de canjiquinha e soja (80:20 e 70:30), e verificar suas características sensoriais, quando aromatizados para uso como petiscos.

\section{Material e Métodos}

As matérias-primas usadas para os estudos foram a canjiquinha e grãos de soja (Glycine max (L.) Merrill, variedade BRS-155, safra de 1999), adquiridos, respectivamente, no comércio e na Embrapa-Centro Nacional de Pesquisa de Soja, Londrina, PR.

A obtenção da farinha extrusada e todas as análises químicas, físicas e da atividade do inibidor de tripsina foram feitas em triplicata.

Em relação à canjiquinha, grãos de soja integrais e decorticados, e farinha mista crua de canjiquinha e soja, foram realizadas análises de umidade, extrato etéreo, proteína bruta e cinzas, segundo métodos da American Association of Cereal Chemists (1995), e de fibra bruta, conforme Kamer \& Ginkel (1952).

Os grãos de soja foram decorticados e branqueados, conforme Wang et al. (2001). Em seguida, os mesmos grãos de soja foram misturados com a canjiquinha nas proporções de 20:80 e 30:70 (base seca), e desintegrados num moinho de facas e martelos, com peneira de $2 \mathrm{~mm}$. Foram obtidas duas farinhas mistas cruas de canjiquinha e soja (80:20 e 70:30) com aproximadamente 19 e $21 \%$ de umidade, respectivamente. Ambas as farinhas mistas cruas foram extrusadas em extrusor Brabender de dupla rosca, com velocidade de alimentação constante de $20,8 \mathrm{~kg} / \mathrm{h}$, rotação de parafuso de $100 \mathrm{rpm}$ e diâmetro de matriz de $5 \mathrm{~mm}$.
As temperaturas de barril do extrusor foram constantes na zona $1\left(60^{\circ} \mathrm{C}\right)$ e na zona $2\left(90^{\circ} \mathrm{C}\right)$ e variáveis na zona $3(90$, 110,130 e $\left.150^{\circ} \mathrm{C}\right)$ e na zona 4 , matriz $\left(110,130\right.$ e $\left.150^{\circ} \mathrm{C}\right)$. Os produtos extrusados expandidos foram designados de acordo com as temperaturas a que foram submetidos no extrusor, pelo que se segue: 90-110 (A); 90-130 (B); 90-150 (C); 110-110 (D); 110-130 (E); 110-150 (F); 130-130 (G); 130-150 (H); 150-150 (I). Os produtos extrusados expandidos foram secados numa estufa a $60^{\circ} \mathrm{C}$ com circulação de ar por período de 5 a 6 horas, obtendose os produtos extrusados expandidos com aproximadamente 4 a $5 \%$ de umidade.

A determinação do índice de expansão (IE) foi realizada conforme Gujska \& Khan (1991); consiste na relação entre o diâmetro do produto extrusado expandido e o diâmetro da matriz. Foram feitas 10 determinações em cada amostra.

$\mathrm{Na}$ determinação do índice de solubilidade em água (ISA), foram moídos os produtos extrusados expandidos secos num moinho de martelo, obtendo-se, então, suas respectivas farinhas com cerca de 4 a $7 \%$ de umidade. O ISA foi determinado segundo Anderson et al. (1969).

Nas amostras submetidas à avaliação sensorial, foi analisada a atividade do inibidor de tripsina conforme Kakade et al. (1969).

Antes da avaliação sensorial, os provadores foram selecionados quanto à sua capacidade em detectar diferenças. A seleção foi feita com teste triangular, usando-se os produtos extrusados expandidos em estudo. Mediante análise seqüencial, foram selecionados 10 provadores, que foram treinados durante 10 semanas, com as mesmas amostras, usando-se produto extrusado expandido de canjiquinha como controle. Sessões preliminares foram feitas para explicar o que constituía uma qualidade boa ou ruim. Na avaliação, os atributos considerados em relação à aparência foram cor e expansão; em relação à textura, foram dureza, fraturabilidade, mastigabilidade, gomosidade, adesividade e recobrimento na boca; e quanto ao sabor, foram sabor de feijão cru, adstringência e amargor.

Foram selecionados dois produtos extrusados expandidos, que apresentaram maiores valores de IE e ISA, os quais foram submetidos ao teste sensorial de qualidade (aparência, textura e sabor), utilizando-se a Escala Estruturada de 9 pontos (1: extremamente ruim; 9: excelente) e a equipe de 10 provadores previamente treinados, de ambos os sexos.

Entre os produtos extrusados expandidos avaliados, foi selecionado apenas um que obteve maiores escores de textura e de sabor, sendo ao mesmo acrescentado $1 \%$ de sal e $1 \%$ de aromatizante com bacon, cebola ou queijo, obtendo-se assim, petiscos com três aromas. Os petiscos foram posteriormente submetidos ao teste massal de preferên- 
cia, usando-se a Escala Hedônica de 9 pontos (1: desgostei muitíssimo; 9: gostei muitíssimo), e uma equipe de 120 provadores não treinados.

Em relação aos resultados de IE dos produtos extrusados expandidos e ISA de suas farinhas, foi usado o delineamento inteiramente casualizado. Em relação aos testes sensoriais com duas e três amostras, foi usado o delineamento em blocos casualizados. Os dados de IE, ISA e dos testes sensoriais foram submetidos à análise de variância e as médias comparadas pelo teste de Tukey a 5\% de probabilidade. As análises estatísticas foram realizadas segundo Pimentel-Gomes (1991).

\section{Resultados e Discussão}

A composição centesimal aproximada obtida para a canjiquinha (Tabela 1) foi semelhante à encontrada por Borges et al. (1999). A soja apresentou teores de proteína, extrato etéreo, cinzas e fibra bruta maiores do que a canjiquinha, e foram superiores aos valores obtidos por Maia et al. (2000), em virtude da cultivar e do ano do plantio. Os conteúdos de proteína e extrato etéreo dos grãos de soja decorticados foram maiores do que os dos grãos de soja integrais. $\mathrm{O}$ alto teor de fibra bruta da soja integral indica que a casca contém grande quantidade deste componente. Por outro lado, a canjiquinha mostrou o maior teor de carboidratos. Por isso, os teores de proteína (de 7,84 a $18,38 \%$ ), extrato etéreo (de 0,49 a $7,05 \%$ ), cinzas (de 0,29 a 1,82\%) e fibra bruta (de 0,44 a 1,37\%) aumentaram com o aumento das proporções de soja (de 0 a $30 \%$ ) nas farinhas mistas cruas de canjiquinha e soja, enquanto o porcentual de carboidratos (de 90,94 a 71,38\%) diminuiu com o aumento das proporções de soja. Resultados quanto à composição centesimal aproximada da farinha mista crua de canjiquinha e soja (70:30) são semelhantes aos encontrados por Gutiérrez \& Gómez (1987).
Os produtos extrusados expandidos contendo $20 \%$ de soja apresentaram índice de expansão (IE) maior do que aqueles com $30 \%$ de soja (Tabela 2). Isto está de acordo com o observado por Gujska \& Khan (1991), que constataram que o conteúdo de proteína foi negativamente correlacionado com a expansão. O efeito de proteína poderia ter sido dependente tanto do tipo como do conteúdo de proteína. Bhatnagar \& Hanna (1994) constataram que a diminuição da expansão de amidos extrusados, devido à complexação com lipídio, poderia ser causada pelo decréscimo na proporção de amilose livre para amilopectina. Estudos de Chinnaswamy \& Hanna (1988) levaram à conclusão de que existe uma proporção ótima de amilose e amilopectina para uma expansão máxima de amidos extrusados, o que indica a contribuição de ambas para a expansão. Conforme Launay \& Lisch (1983), durante a extrusão do amido, a expansão depende da formação da matriz de amido, a qual, no caso, induz à formação de vapores de água. Conforme Bhatnagar \& Hanna (1994), a adição de lipídio poderia afetar as características da matriz de amido, de modo a diminuir sua capacidade de retenção de vapores de água, resultando numa menor expansão. Desta forma, acredita-se que a diminuição do IE observada no presente trabalho possa ser explicada pela diminuição do conteúdo de amido e o aumento do teor de proteína (de 14,83 para 18,38\%) e de lipídio (de 4,84 para 7,05\%), em virtude do incremento da proporção de soja (de 20 para $30 \%$ ) nas farinhas mistas com canjiquinha. $\mathrm{O}$ aumento do teor de umidade (de 19 para $21 \%$, respectivamente, nas misturas 80:20 e 70:30) das farinhas mistas cruas de canjiquinha e soja pode também ter contribuído para o decréscimo do IE. Chinnaswamy \& Hanna (1990) também verificaram que o IE diminuiu com o aumento dos conteúdos de umidade de amido.

Tabela 1. Composição centesimal aproximada (\% base seca) da canjiquinha, dos grãos de soja integrais e decorticados, e das farinhas mistas cruas de canjiquinha e soja (80:20 e 70:30).

\begin{tabular}{lccccc}
\hline Composição (\%) & Canjiquinha & Soja integral & Soja decorticada & \multicolumn{2}{c}{$\begin{array}{c}\text { Proporção de canjiquinha e soja } \\
\text { nas farinhas mistas cruas }\end{array}$} \\
\cline { 5 - 6 } & & & & $80: 20$ & $70: 30$ \\
\hline Proteína & 7,84 & 41,16 & 44,57 & 14,83 & 18,38 \\
Extrato etéreo & 0,49 & 20,97 & 23,62 & 4,84 & 7,05 \\
Cinzas & 0,29 & 5,69 & 5,54 & 1,29 & 1,82 \\
Fibra bruta & 0,44 & 5,93 & 3,67 & 1,02 & 1,37 \\
Carboidratos $^{(1)}$ & 90,94 & 26,25 & 22,60 & 78,02 & 71,38 \\
\hline
\end{tabular}

${ }^{(1)}$ Calculado por diferença (100 - proteína - extrato etéreo - cinzas - fibra bruta). 
Os produtos extrusados expandidos contendo 20 e $30 \%$ de soja mostraram um aumento no IE com o aumento da temperatura de barril (TB) na zona 3 até $110^{\circ} \mathrm{C}$, e acima desta temperatura este índice diminuiu. Por outro lado, o IE aumentou com o aumento da TB na zona 4 , exceto nos submetidos à $\mathrm{TB}$ a $130 \mathrm{e} 150^{\circ} \mathrm{C}$ na zona 3 (Tabela 2). A explicação, de acordo com Chen et al. (1991), seria de que os materiais crus se tornam mais viscosos em baixas temperaturas, resultando em menor expansão de produtos, enquanto em altas temperaturas, uma dextrinização excessiva juntamente com uma estrutura enfraquecida poderiam também resultar numa expansão reduzida desses produtos.

Assim, conforme os resultados obtidos no presente trabalho, sugere-se que o IE dos produtos extrusados expandidos de misturas de canjiquinha e soja contendo 20 e $30 \%$ de soja depende tanto do conteúdo de umidade quanto da TB, além da composição química das matérias-primas, uma vez que as demais variáveis do processo de extrusão foram idênticas em ambos os casos. O fator da composição química de farinha mista crua de canjiquinha e soja é considerado predominante, uma vez que o amido é o componente responsável pela expansão.

Do aumento da TB na zona 3 resultou um aumento do índice de solubilidade em água (ISA) até a temperatura de $110^{\circ} \mathrm{C}$, além da qual, o ISA passou a diminuir (Tabela 2). Por outro lado, o ISA aumentou com o aumento da TB na zona 4, exceto nas que foram submetidas à $\mathrm{TB}$ a 130 e $150^{\circ} \mathrm{C}$ na zona 3 . As farinhas de produtos extrusados expandidos contendo $20 \%$ de soja apresentaram valores maiores de ISA do que aquelas com $30 \%$ de soja.

Gutiérrez \& Gómez (1987) constataram que o valor de ISA foi tomado como indicativo da degradação sucessiva de amido, uma vez que seu valor aumentou à medida que as cadeias amiláceas se reduziam, como conseqüência do tratamento sofrido no extrusor. Os valores elevados de ISA corresponderam às misturas dextrinizadas, e o aumento do valor de ISA foi observado nas amostras gelatinizadas e dextrinizadas. Chinnaswamy \& Hanna (1990) e Tang \& Ding (1994) também verificaram que o ISA aumentou notavelmente com o aumento da TB e com a diminuição do conteúdo de umidade. Além da fragmentação do amido, o conteúdo de proteína pode também afetar o ISA. Pois, segundo Gujska \& Khan (1991), à medida que aumentava a quantidade de proteína, o processo de extrusão diminuiu o ISA das misturas de milho com diversas frações altamente protéicas de leguminosas, mostrando a desnaturação e a insolubilização da fração protéica com o aumento da temperatura. Por outro lado, Chauhan \& Bains (1985) observaram que o ISA das misturas extrusadas de arroz aumentou nitidamente após a adição de farinha de soja desengordurada, resultado atribuído ao alto conteúdo de proteínas solúveis da soja. O efeito de lipídio sobre o ISA relatado na literatura também é controverso. Conforme Bhatnagar \& Hanna (1994), o decréscimo do ISA

Tabela 2. Índice de expansão dos produtos expandidos e índice de solubilidade em água das farinhas de produtos expandidos de misturas de canjiquinha e soja nas proporções de 80:20 e 70:30, obtidos por processo de extrusão em diferentes temperaturas de barril ${ }^{(1)}$.

\begin{tabular}{|c|c|c|c|c|c|c|}
\hline \multirow{3}{*}{$\begin{array}{l}\text { Identificação } \\
\text { do produto } \\
\text { expandido }\end{array}$} & \multicolumn{2}{|c|}{ Temperatura de barril $\left({ }^{\circ} \mathrm{C}\right)$} & \multicolumn{2}{|c|}{ Índice de expansão } & \multirow{2}{*}{\multicolumn{2}{|c|}{$\begin{array}{l}\text { Índice de solubilidade em água (\%) } \\
\text { Proporção de canjiquinha e soja }\end{array}$}} \\
\hline & \multirow[t]{2}{*}{ Zona 3} & \multirow[t]{2}{*}{ Zona 4} & \multicolumn{2}{|c|}{ Proporção de canjiquinha e soja } & & \\
\hline & & & $80: 20$ & $70: 30$ & $80: 20$ & $70: 20$ \\
\hline $\mathrm{A}$ & 90 & 110 & $2,80 \mathrm{~cd}$ & $1,44 \mathrm{ecc}$ & $45,61 d$ & $25,38 \mathrm{~d}$ \\
\hline B & & 130 & $2,90 \mathrm{cc}$ & $1,48 \mathrm{ecc}$ & $59,85 \mathrm{c}$ & $26,72 \mathrm{~cd}$ \\
\hline $\mathrm{C}$ & & 150 & $3,10 \mathrm{bc}$ & $1,60 \mathrm{cdc}$ & $65,41 b$ & $28,80 \mathrm{bc}$ \\
\hline $\mathrm{D}$ & 110 & 110 & $3,16 \mathrm{bc}$ & $1,72 \mathrm{abc}$ & $67,23 \mathrm{ab}$ & $26,79 \mathrm{~cd}$ \\
\hline $\mathrm{E}$ & & 130 & $3,40 \mathrm{ac}$ & 1,76 acc & $69,32 \mathrm{a}$ & $29,39 b$ \\
\hline $\mathrm{F}$ & & 150 & $3,44 \mathrm{ac}$ & $1,80 \mathrm{acc}$ & $69,43 a$ & $36,00 \mathrm{a}$ \\
\hline G & 130 & 130 & $3,10 \mathrm{bc}$ & $1,70 \mathrm{abc}$ & $64,40 \mathrm{~b}$ & $27,91 b c$ \\
\hline $\mathrm{H}$ & & 150 & $2,86 \mathrm{~cd}$ & $1,64 \mathrm{bcd}$ & $48,00 \mathrm{~d}$ & $24,92 d$ \\
\hline I & 150 & 150 & $2,76 \mathrm{dc}$ & $1,54 \mathrm{dec}$ & $40,80 \mathrm{e}$ & $20,82 \mathrm{e}$ \\
\hline $\mathrm{CV}(\%)$ & & & 2,76 & 5,13 & 2,02 & 2,77 \\
\hline
\end{tabular}

(1)As médias, na mesma coluna, seguidas de letras diferentes diferem entre si pelo teste de Tukey a 5\% de probabilidade; temperaturas constantes no extrusor: $60^{\circ} \mathrm{C}$ (zona 1) e $90^{\circ} \mathrm{C}$ (zona 2). 
ocorreu por causa da insolubilização da amilose complexada com o lipídio e também pela degradação diminuída de amilopectina, devido ao efeito lubrificante do lipídio. Contudo, Lorenz (1976) verificou que o agregado de lipídio e amido mostrou o ISA $(14,73 \%)$ maior do que o amido sozinho (1,29\%).

Assim, o presente trabalho sugere que o ISA das farinhas de produtos extrusados expandidos de misturas de canjiquinha e soja com 20 e $30 \%$ de soja teria sido influenciado, não só por umidade e TB, mas também pela composição química, como amido, proteína e lipídio das matérias-primas, já que as demais variáveis do processo de extrusão foram idênticas em ambos os casos. O aumento do ISA se deve, provavelmente, à fragmentação do amido, aumentando a quantidade de sólidos solúveis presentes. Porém, deve-se levar em conta que também a desnaturação de proteína pode favorecer a reação de escurecimento não-enzimático, que, por conseqüência, propicia a formação de agregado, diminuindo o seu ISA.

A solubilidade é considerada por Cheftel et al. (1989) uma característica importante numa bebida, uma vez que boa solubilidade inicial permite uma dispersão rápida e completa das proteínas, conduzindo a um sistema coloidal finamente disperso com estrutura macroscópica homogênea e textura suave. Portanto, as farinhas obtidas a partir de produtos extrusados expandidos de misturas de canjiquinha e soja com $20 \%$ de soja estudadas no presente trabalho devem ser recomendadas, em vez das misturas de canjiquinha com $30 \%$ de soja, para serem usadas em bebida, especialmente as que contêm valores altos de ISA.

Segundo Tang \& Ding (1994), as mudanças do IE que ocorrem durante a extrusão estão intimamente ligadas ao grau de degradação macromolecular da amilopectina do amido de milho. A determinação do IE foi usada naquele estudo como indicativo do grau de degradação macromolecular do amido, o qual foi representado por ISA. A máxima expansão ocorreu quando o conteúdo de carboidratos solúveis atingiu $30 \%$. Estas observações apresentaram boa correlação com os resultados encontrados no presente trabalho, no qual foi verificada uma correlação positiva entre IE dos produtos extrusados expandidos de misturas de canjiquinha e soja e ISA de suas fari- nhas, com coeficientes de correlação iguais a 0,8437 e 0,5351 , respectivamente, nos produtos com 20 e $30 \%$ de soja, ambos significativos a $5 \%$ de probabilidade.

Não houve atividade do inibidor de tripsina (AIT) nos produtos extrusados expandidos de misturas de canjiquinha e soja (80:20) selecionados para a avaliação sensorial, o que indica que o processo de extrusão, sob temperatura de barril de $60,90,110$ e $130^{\circ} \mathrm{C}$ e de 60 , $90,110 \mathrm{e} 150^{\circ} \mathrm{C}$, foi adequado para inativar o inibidor de tripsina. Guzman et al. (1989) observaram que a inativação da AIT aumentou com o aumento da temperatura de saída do extrusor (de 120 a $160^{\circ} \mathrm{C}$ ); e de acordo com Lorenz \& Jansen (1980), a inativação da AIT aumentou para $80 \%$ com a adição de água para uma mistura crua. Segundo esses autores, a adição de 3\% de água aumentou a inativação da AIT de 30,6 para 53,7\% em grãos de soja integrais, e de 39,1 para $67,8 \%$ em grãos de soja decorticados.

Os produtos extrusados expandidos de misturas de canjiquinha e soja (80:20) E e F não mostraram diferenças significativas entre si em relação à aparência (Tabela 3). Porém, em relação à textura e ao sabor, o produto extrusado expandido $\mathrm{F}$ apresentou melhores escores do que o E. O petisco aromatizado com cebola $(8,58)$ obteve melhor resultado no teste massal de preferência do que os petiscos aromatizados com bacon $(8,03)$ e queijo $(8,15)$, embora todos os três aromas estudados tenham apresentado escores acima de 8,0, ou seja, muito bom.

Oliveira et al. (1997) constataram que a cor e a expansão se correlacionaram com a aparência de biscoitos elaborados com fubá e soja, ou seja, para que os biscoitos apresentassem boa aparência, necessi-

Tabela 3. Escores da avaliação sensorial de aparência, textura e sabor para produtos expandidos de misturas de canjiquinha e soja na proporção de 80:20, obtidos pelo processo de extrusão em diferentes temperaturas de barril $^{(1)}$.

\begin{tabular}{cccccc}
\hline \multirow{2}{*}{$\begin{array}{l}\text { Identificação } \\
\text { do produto }\end{array}$} & \multicolumn{2}{c}{ Temperatura de barril $\left({ }^{\circ} \mathrm{C}\right)$} & Aparência & Textura & Sabor \\
\cline { 2 - 6 } expandido & Zona 3 & Zona 4 & & & \\
\hline E & 110 & 130 & $8,50 \mathrm{a}$ & $8,20 \mathrm{~b}$ & $8,00 \mathrm{~b}$ \\
$\mathrm{~F}$ & 110 & 150 & $8,35 \mathrm{a}$ & $8,55 \mathrm{a}$ & $8,55 \mathrm{a}$ \\
\hline $\mathrm{CV}(\%)$ & - & - & 7,83 & 6,29 & 5,17 \\
\hline
\end{tabular}

(1)As médias, na mesma coluna, seguidas de letras diferentes diferem entre si pelo teste de Tukey a $5 \%$ de probabilidade; temperaturas constantes no extrusor: $60^{\circ} \mathrm{C}$ (zona 1 ) e $90^{\circ} \mathrm{C}$ (zona 2). 
tou-se de um equilíbrio entre os parâmetros de cor e expansão. Conforme Chen et al. (1991), a intensidade de cor dos extrusados de milho diminuiu, porém a sua expansão aumentou, com o aumento da TB no extrusor, pois o grau de decomposição dos pigmentos de milho aumentou e a viscosidade do material diminuiu, resultando em aparência com cor mais clara e expansão mais fácil dos extrusados. Segundo esses autores, em uma umidade menor, a sua distribuição foi mais uniforme, propiciando massa mais elástica, com textura de superfície mais lisa, e favorecendo também a sua expansão. Portanto, acredita-se que, nos experimentos realizados no presente trabalho, o aumento da $\mathrm{TB}$ nas zonas 3 (até $110^{\circ} \mathrm{C}$ ) e 4 (até 130 ou $150^{\circ} \mathrm{C}$ ) tenha resultado na diminuição da cor amarela de canjiquinha nos produtos extrusados expandidos de misturas de canjiquinha e soja (80:20 e 70:30), além de seu aumento na expansão. Os produtos extrusados expandidos com $20 \%$ de soja apresentaram IE maiores do que os com $30 \%$ de soja, por causa do menor conteúdo de umidade. Contudo, a diminuição da cor foi compensada pela adição de soja (20 e 30\%), devido à cor também amarelada da soja. Portanto, os produtos extrusados expandidos E e F contendo $20 \%$ de soja, submetidos às respectivas $\mathrm{TB}$ em $60,90,110$ e 130 e $60,90,110$ e $150^{\circ} \mathrm{C}$, que tiveram os mesmos IE, também mostraram os mesmos escores de aparência, não havendo diferenças significativas entre si.

Em relação à textura, Chen et al. (1991) verificaram que a TB teve efeito significativo sobre a crocância e a mastigabilidade dos extrusados de milho. A crocância foi intimamente relacionada com a densidade, a qual, por sua vez, se correlacionou com a expansão. Um aumento da TB resultou em aumento da expansão, obtendo-se um produto menos denso com maior crocância e mais fácil de ser mastigado. Estes resultados foram confirmados no presente trabalho, no qual se observou que o produto extrusado expandido F com maior valor numérico de IE apresentou melhores escores de textura do que o produto E (Tabela 3).

O mesmo comportamento ( $F$ superior a $E$ ) foi verificado nos escores de sabor, o que pode ser, provavelmente, explicado por Chen et al. (1991), os quais constataram que o aroma de farinha crua (desagradável) diminuiu, e o sabor de milho torrado (agradá- vel) aumentou nos extrusados de milho, à medida que a TB aumentava, em quaisquer condições de umidade.

\section{Conclusões}

1. O índice de expansão (IE) dos produtos extrusados expandidos obtidos a partir de misturas de canjiquinha e soja e o índice de solubilidade em água (ISA) de suas farinhas aumentam com o aumento da temperatura de barril (TB) na zona 3 do extrusor até $110^{\circ} \mathrm{C}$, além da qual, eles diminuem.

2. O aumento da TB na zona 4 do extrusor resulta em acréscimo do IE dos produtos extrusados expandidos de misturas de canjiquinha e soja, e em aumento do ISA de suas farinhas, exceto nos submetidos à $\mathrm{TB}$ de $130^{\circ} \mathrm{C}$ e $150^{\circ} \mathrm{C}$ na zona 3 .

3. Os produtos extrusados expandidos da mistura de canjiquinha e soja contendo $20 \%$ de soja apresentam IE e ISA maiores que os produtos com $30 \%$ de soja.

4. O produto extrusado expandido da mistura de canjiquinha e soja contendo $20 \%$ de soja e submetido às temperaturas de barril de $60,90,110$ e $150^{\circ} \mathrm{C}$ apresenta melhor aparência, textura e sabor, e quando aromatizado com cebola para uso como petisco, apresenta preferência superior.

\section{Referências}

AMERICAN ASSOCIATION OF CEREAL CHEMISTS (Saint Paul, Estados Unidos). Approved methods of the American Association of Cereal Chemists. 9. ed. St. Paul, 1995. 2 v.

ANDERSON, R. A.; CONWAY, H. F.; PFEIFER, V. F.; GRIFFIN JUNIOR, E. L. Gelatinization of corn grits by roll- and extrusion-cooking. Cereal Science Today, St. Paul, v. 14, n. 1, p. 4-12, 1969.

BHATNAGAR, S.; HANNA, M. A. Amylose-lipid complex formation during single-screw extrusion of various corn starches. Cereal Chemistry, St. Paul, v. 71, n. 6, p. 582-587, 1994.

BORGES, G. G.; WANG, S.-H.; CABRAL, L. C.; MAIA, L. H.; ASCHERI, J. L. R. Caracterización química de papillas deshidratadas de grits de maíz e soya. Alimentaria, Madrid, v. 36, n. 305, p. 111-114, 1999. 
CHAUHAN, G. S.; BAINS, G. S. Effect of defatted soy flour on the physico-chemical characteristics of extruded rice products. Journal of Food Science and Technology, Mysore, v. 22, n. 2, p. 115-118, 1985.

CHEFTEL, J. C.; CUQ, J. L.; LORIENT, D. Proteínas alimentarias. Zaragoza: Acribia, 1989. 346 p.

CHEN, J.; SERAFIN, F. L.; PANDYA, R. N.; DAUN, H. Effects of extrusión conditions on sensory properties of corn meal extrudates. Journal of Food Science, Chicago, v. 56, n. 1 , p. $84-89,1991$.

CHINNASWAMY, R.; HANNA, M. A. Macromolecular and functional properties of native and extrusion-cooked corn starch. Cereal Chemistry, St. Paul, v. 67, n. 5, p. 490499, 1990.

CHINNASWAMY, R.; HANNA, M. A. Relationship between amylose content and extrusion-expansion properties of corn starches. Cereal Chemistry, St. Paul, v. 65 , n. 2 , p. $138-143,1988$.

GUJSKA, E.; KHAN, K. Functional properties of extrudates from high starch fractions of navy and pinto beans and corn meal blended with legume high protein fractions. Journal of Food Science, Chicago, v. 56, n. 2, p. 431-435, 1991.

GUTIÉRREZ, M. V. G. de; GÓMEZ, M. H. Modelo para la extrusión de mezclas maíz:soja (70:30). Archivos Latinoamericanos de Nutrición, Guatemala, v. 37, n. 3, p. 494-502, 1987.

GUZMAN, G. J.; MURPHY, P. A.; JOHNSON, L. A. Properties of soybean-corn mixtures processed by lowcost extrusion. Journal of Food Science, Chicago, v. 54, n. 6, p. 1590-1593, 1989.

KAKADE, M. L.; SIMONS, N. R.; LIENER, I. E. An evaluation of natural vs. synthetic substrates for measuring the antitryptic activity of soybean samples. Cereal Chemistry, St. Paul, v. 46, n. 5, p. 518-526, 1969.

KAMER, J. H. van de; GINKEL, L. van. Rapid determination of crude fiber in cereals. Cereal Chemistry, St. Paul, v. 29, n. 4, p. 239-251, 1952.

LAUNAY, B.; LISCH, J. M. Twin-screw extrusion cooking of starch: behavior of starch pastes, expansion and mechanical properties of extrudates. Journal of Food Engineering, Essex, v. 2, n. 3, p. 259-280, 1983.
LORENZ, K. Physico-chemical properties of lipid-free cereal starches. Journal of Food Science, Chicago, v. 41, n. 6, p. 1357-1359, 1976.

LORENZ, K.; JANSEN, G. R. Nutrient stability of fullfat soy flour and corn-soy blends produced by low-cost extrusion. Cereal Foods World, St. Paul, v. 25, n. 4, p. 161172,1980 .

MAIA, L. H.; WANG, S.-H.; FERNANDES, M. S.; CABRAL, L. C. Características químicas dos mingaus desidratados de arroz e soja. Ciência e Tecnologia de Alimentos, Campinas, v. 20, n. 3, p. 416-423, 2000.

MERCIER, C.; CHARBONNIERE, R.; GREBAUT, J.; DE LA GUERIVIERE, J. F. Formation of amylose-lipid complexes by twin-screw extrusion cooking of manioc starch. Cereal Chemistry, St. Paul, v. 57, n. 1, p. 4-9, 1980.

OLIVEIRA, D. R.; WANG, S.-H.; SGARBIERI, V. C. Propriedades nutricionais e sensoriais de biscoitos à base de milho e soja, cozidos em forno de microondas. Pesquisa Agropecuária Brasileira, Brasília, v. 32, n. 3, p. 333338, mar. 1997.

OWUSU-ANSAH, J.; VOORT, F. R. van de; STANLEY, D. W. Physicochemical changes in cornstarch as a function of extrusion variables. Cereal Chemistry, St. Paul, v. 60, n. 4, p. 319-324, 1983.

PIMENTEL-GOMES, F. Curso de estatística experimental. 13. ed. São Paulo: Nobel, 1991. 468 p.

TANG, J.; DING, X. L. Relationship between functional properties and macromolecular modifications of extruded corn starch. Cereal Chemistry, St. Paul, v. 71, n. 4, p. 364369, 1994.

WANG, S.-H.; ASCHERI, J. L. R.; OLIVEIRA, M. F.; FERNANDES, M. S. Características tecnológicas y sensoriales de harinas de arroz-soya (70:30) extruídas para uso como papilla instantanea. Alimentaria, Madrid, v. 38, n. 324, p. 77-84, 2001.

ZOIA, W. F.; WANG, S.-H.; SGARBIERI, V. C. Características sensoriais e nutricionais de angus fortificados com diferentes níveis de farinha de soja desengordurada. Alimentos e Nutrição, São Paulo, v. 8, p. 49-56, 1997. 